\title{
Expression of CD39 mRNA is altered in the peripheral blood of patients with allergic asthma
}

\author{
LIN-LIN WANG $^{1}$, PING-HUA TANG ${ }^{2}$, CHAO-GUO SHI $^{1}$, YING-HUAN WAN $^{1}$, \\ WEI TANG ${ }^{1}$, XIA-XIAO HOU ${ }^{1}$, NA-LI PAN ${ }^{1}$, YU-BAO SHI ${ }^{1}$ and QIN-LIAN TAO ${ }^{1}$ \\ ${ }^{1}$ Department of Pulmonary Medicine, Ruijin Hospital, Shanghai Jiao Tong University School of Medicine, \\ Shanghai 200025; ${ }^{2}$ Department of Pulmonary Medicine, Qingdao Municipal Hospital, \\ Qingdao University School of Medicine, Qingdao, Shandong 266011, P.R. China
}

Received March 21, 2013; Accepted October 03, 2013

DOI: $10.3892 / b r .2013 .196$

\begin{abstract}
The ectoenzyme CD39 hydrolyzes extracellular adenosine 5'-triphosphate (ATP), which possesses pro-inflammatory properties. However, the role of CD39 in allergic asthma has not been fully elucidated. A total of 18 patients with persistent asthma who were allergic to house dust mites and 19 healthy volunteers were enrolled in this study. The expression of CD39, GATA3, RAR-related orphan receptor $\gamma(\mathrm{ROR}-\gamma \mathrm{t}$ ) and forkhead box P3 (FoxP3) mRNA in peripheral blood mononuclear cells (PBMCs) was determined by SYBR-Green I quantitative polymerase chain reaction (qPCR). The cytokines interleukin (IL)-4, IL-17A, transforming growth factor $\beta$ (TGF- $\beta$ ) and DP.sIgE were detected by enzyme-linked immunosorbent assay. Our data demonstrated that the expression of CD39 mRNA in PBMCs from asthmatic patients was significantly lower compared to that in normal controls $\left[(1.49 \pm 0.59) \times 10^{-3}\right.$ vs. $(2.17 \pm 0.77) \times 10^{-3}$, respectively; $\mathrm{P}<0.01]$. CD39 mRNA was negatively correlated with serum IL-4, IL-17A and GATA3 expression ( $r=-0.468$, $\mathrm{P}<0.05 ; \mathrm{r}=-0.550, \mathrm{P}<0.05$; and $\mathrm{r}=-0.424, \mathrm{P}<0.01$, respectively) and positively correlated with FoxP3 and TGF- $\beta$ expression $(r=0.373, P<0.05$; and $r=0.425, P<0.05$, respectively). There was no obvious correlation between CD39 and ROR- $\gamma$ t expression $(\mathrm{r}=-0.259, \mathrm{P}=0.122)$. These data suggested that $\mathrm{CD} 39 \mathrm{mRNA}$ expression was downregulated in allergic asthma, which was positively correlated with serum IL-4, IL-17A and GATA3 expression and negatively correlated with serum TGF- $\beta$ and FoxP3 expression, whereas there was no correlation with ROR- $\gamma \mathrm{t}$. Therefore, it was hypothesized that CD39 may participate in the occurrence and progression of allergic asthma.
\end{abstract}

Correspondence to: Professor Chao-Guo Shi, Department of Pulmonary Medicine, Ruijin Hospital, Shanghai Jiao Tong University School of Medicine, 197 Ruijin Er Road, Luwan District, Shanghai 200025, P.R. China

E-mail: shiguochao@hotmail.com

Key words: allergic asthma, CD39, inflammatory factors

\section{Introduction}

The introduction of Global Initiative for Asthma (GINA) guidelines has enabled more patients with allergic asthma to control their disease. However, a high percentage of asthmatic patients are not efficiently controlled with the currently available therapies and a high percentage of patients are not compliant with inhaled treatments for asthma. Therefore, it is crucial to improve our understanding of the pathophysiology of asthma.

CD39 is a cell surface-located prototypic member of the ectonucleoside triphosphate diphosphohydrolase (E-NTPDase) family. This ectoenzymatic cascade in tandem with ecto-5'-nucleotidase (CD73) generates adenosine and exerts significant effects on adenosine 5'-triphosphate (ATP) and adenosine receptor signalling (P2 and P1 purinergic receptors, respectively). CD39 was first described as a B lymphocyte activation marker (1). This ectonucleotidase is also expressed on natural killer cells, monocytes, dendritic cells (DCs) and subsets of activated T cells (2). CD39 also catalyzes extracellular ATP released by inflammatory, damaged and activated T cells (3-7). However, extracellular ATP exerts pro-inflammatory effects, such as promoting monocytes and lymphocytes to secrete interleukin (IL)-1 and IL-8 (8-9), promoting the differentiation and migration of DCs (10) and IL-17 expression and inducing the apoptosis of regulatory T cells (11-12). Therefore, CD39 may alleviate the inflammatory damage of tissue by removing extracellular ATP.

However, the expression of CD39 in peripheral blood mononuclear cells (PBMCs) in allergic asthma and its functions have not been elucidated. Our study initially investigated the expression of CD39 in the peripheral blood of patients with allergic asthma and analyzed the correlations between CD39 mRNA and serum IL-4, IL-17A, transforming growth factor $\beta$ (TGF- $\beta$ ) and GATA3, RAR-related orphan receptor $\gamma($ ROR- $\gamma t$ ) and forkhead box P3 (FoxP3) mRNA.

\section{Materials and methods}

Subjects and sample preparation. A total of 18 patients with chronic persistent allergic asthma, as determined by the positive results of allergen tests to house dust mites, were recruited 
in this study. Brief lung function tests, including forced expiratory volume in the first second (FEV1) (\% predicted), were performed. The concentration of DP.sIgE was measured. None of the patients had been treated with systemic glucocorticoids within one month prior to the initiation of the study and had never received other immunosuppressive agents or desensitization therapy. A total of 19 age- and gender-matched healthy donors, with normal pulmonary function and negative allergen tests, were selected as normal controls. FEV1 (\% predicted) was markedly lower and DP.sIgE was markedly higher in asthmatic patients compared to those in normal controls (Table I).

Written informed consent was obtained from all the individuals and the study received ethical approval from the Research Ethics Board of Ruijin Hospital, Shanghai Jiao Tong University School of Medicine.

Main reagents and instruments. The human lymphocyte separation medium and the SYBR-Green I quantitative polymerase chain reaction (qPCR) kit were purchased from BioTNT, Shanghai, China; RPMI was provided by Gibco, Carlsbad, CA, USA; the TRIzol mRNA extraction reagent and the ABI ViiA 7 Real-Time PCR system were purchased from Life Technologies, Carlsbad, CA, USA; the cDNA reverse transcription kit was obtained from Promega Corporation, Madison, WI, USA; the human serum IL-4, IL-17A and TGF- $\beta$ enzymelinked immunosorbent assay (ELISA) kits were purchased from Anogen, Mississauga, Canada; the DP.sIgE ELISA kit was provided by Dr. Fooke-Achterrath Laboratorien $\mathrm{GmbH}$, Neuss, Germany; and the Multiskan MS microplate reader was obtained from Ani LabSystems, Ltd., Vantaa, Finland.

Methods. Heparinized peripheral venous blood $(8 \mathrm{ml})$ was collected from each participant. Plasma was isolated from peripheral blood and stored at $-80^{\circ} \mathrm{C}$ until used to measure the concentrations of the cytokines. PBMCs were obtained from peripheral blood by Ficoll-Hypaque density centrifugation $(1,200 \mathrm{x} \mathrm{g}$ for $20 \mathrm{~min}$ at room temperature). The PBMCs were suspended at a density of $2 \times 10^{6}$ cells $/ \mathrm{ml}$ in $1 \mathrm{ml}$ TRIzol reagent and stored at $-80^{\circ} \mathrm{C}$.

The concentrations of DP.sIgE, IL- 4 , IL-17A and TGF- $\beta$ in the plasma were measured by ELISA, in accordance with the manufacturer's instructions. All the measurements were performed in duplicate.

Relative $q P C R$. The total $\mathrm{mRNA}$ in the TRIzol reagent was reverse-transcribed into cDNA. The primers were designed by Life Technologies and synthesized by BioTNT, according to the manufacturer's instructions. For amplification, the SYBR-Green I Real-Time PCR kit was used. Each reaction was run in triplicate on the ABI ViiA 7 Real-Time PCR system and was normalized to housekeeping gene $\beta$-actin transcripts. $\Delta \mathrm{CT}$ values was recorded and converted to $2^{-\Delta \Delta \mathrm{CT}}$, revealing a linear association between the target concentrations and $2^{-\Delta \Delta C T}$ values (the smaller the target concentrations, the smaller the $2^{-\Delta \Delta C T}$ values). The specific primers used are listed in Table II.

Statistical analysis. GraphPad Prism 5 software was used for statistical analysis. Normal distribution and homogeneity of variance in two groups were first tested. If each group exhibited homogeneity, statistical calculations were performed using
Table I. General characteristics of subjects.

\begin{tabular}{lccc}
\hline Index & Asthma & Control & P-value \\
\hline No. & 18 & 19 & - \\
Age (years) & $37.06 \pm 11.67$ & $38.11 \pm 11.37$ & $>0.05$ \\
Gender (M/F) & $12 / 6$ & $13 / 6$ & $>0.05$ \\
FEV1 (\% predicted) & $80.05 \pm 16.72$ & $92.27 \pm 6.54$ & $<0.01$ \\
DP.sIgE (KU/ml) & $28.47 \pm 18.50$ & $0.95 \pm 1.67$ & $<0.01$ \\
\hline
\end{tabular}

FEV1, forced expiratory volume in the first second; M, male; F, female.

Table II. Primer sequences of human CD39, GATA3, ROR- $\gamma \mathrm{t}$ and Foxp3 gene.

\begin{tabular}{|c|c|c|}
\hline Gene & Sequences & $\begin{array}{l}\text { Length } \\
\text { (bp) }\end{array}$ \\
\hline CD39 & $\begin{array}{l}\text { 5'-CTGATTCCTGGGAGCACAT-3' } \\
\text { 5'-GACATAGGTGGAGTGGGAGAG-3' }\end{array}$ & 143 \\
\hline GATA3 & $\begin{array}{l}\text { 5'-GAGATGGCACGGGACACTAC-3' } \\
\text { 5'-GTGGTTGTGGTGGTCTGACAGT-3' }\end{array}$ & 151 \\
\hline $\mathrm{ROR}-\gamma \mathrm{t}$ & $\begin{array}{l}\text { 5'-GGCTCCCTGGATGAATAGAATG-3' } \\
\text { 5'-AGGCAGAGGCAGAAAATGTAAAG-3' }\end{array}$ & 190 \\
\hline FoxP3 & $\begin{array}{l}\text { 5'-ATGCGACCCCCTTTCACCTAC-3' } \\
\text { 5'-TGGCGGATGGCGTTCTTC-3' }\end{array}$ & 155 \\
\hline$\beta$-actin & $\begin{array}{l}\text { 5'-AAGGTGACAGCAGTCGGTT-3' } \\
\text { 5'-TGTGTGGACTTGGGAGAGG-3' }\end{array}$ & 195 \\
\hline
\end{tabular}

ROR- $\gamma$ t, RAR-related orphan receptor $\gamma$; FoxP3, forkhead box P3.

the Student's t-test and the data are presented as means \pm SD. When heteroscedasticity was present in each group, the data were analyzed using the Mann-Whitney U test and presented as medians (interquartile range). Pearson's correlation was used to analyze the relevance. $\mathrm{P}<0.05$ was considered to indicate a statistically significant difference.

\section{Results}

CD39 mRNA expression is decreased in the peripheral blood of patients with allergic asthma. CD39 mRNA expression was markedly lower in patients with allergic asthma compared to that in normal controls $\left[(1.49 \pm 0.59) \times 10^{-3}\right.$ vs. $(2.17 \pm 0.77) \times 10^{-3}$, respectively; $\mathrm{P}<0.01$ ] (Fig. 1).

Increased serum IL-4 and IL-17A levels correlate with CD39 mRNA deficiency in PBMCs. The chronic inflammation of asthma is mediated by several types of inflammatory cytokines, such as IL-4 and IL-17A (13-14). In agreement with our previous studies (15), the levels of IL-4 and IL-17A in the serum were markedly higher in patients with allergic asthma compared to those in normal controls (Table III). We then analyzed the correlation of CD39 mRNA with IL-4 and IL-17A and observed that CD39 mRNA expression was 
Table III. Comparison of serum IL-4, IL-17A and TGF- $\beta$ levels between patients with allergic asthma and normal controls.

\begin{tabular}{lccc}
\hline Cytokine & Asthma & Control & P-value \\
\hline IL-4 & $137.11 \pm 187.42$ & $3.03 \pm 3.01$ & $<0.01$ \\
IL-17A & $54.42 \pm 47.15$ & $15.90 \pm 23.31$ & $<0.01$ \\
TGF- $\beta$ & $66.15 \pm 33.30$ & $164.44 \pm 42.61$ & $<0.01$ \\
\hline
\end{tabular}

IL, interleukin; TGF- $\beta$, transforming growth factor $\beta$.

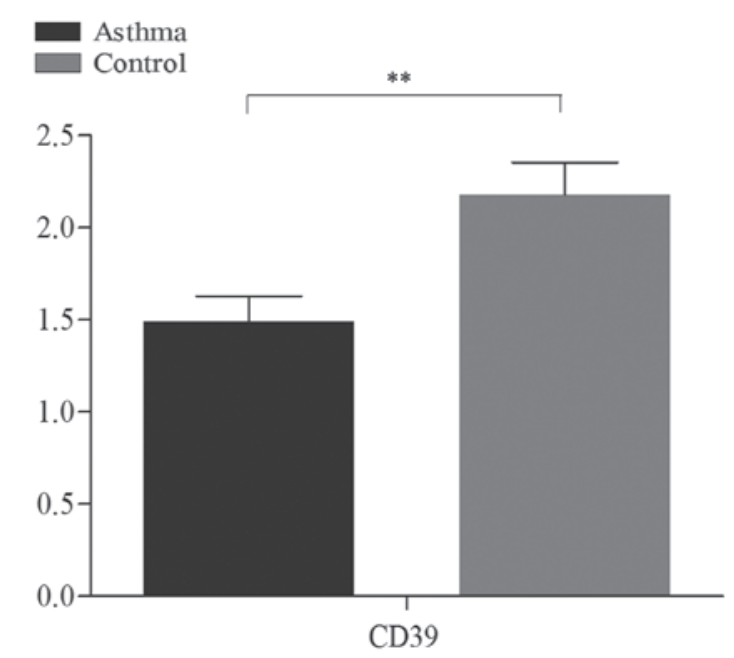

Figure 1. Comparison of CD39 mRNA in peripheral blood mononuclear cells between patients with allergic asthma and normal controls. ${ }^{* *} \mathrm{P}<0.01$.

negatively correlated with IL-4 and IL-17A levels ( $\mathrm{r}=-0.468$, $\mathrm{P}<0.05$; and $\mathrm{r}=-0.550, \mathrm{P}<0.05$, respectively).

Correlation of CD39 mRNA with GATA3 and ROR- $\gamma t$ mRNA. In our study, we further investigated GATA3 and ROR- $\gamma \mathrm{t}$ mRNA expression in PBMCs. We observed that the expression of GATA3 and ROR- $\gamma$ t mRNA was markedly higher in patients with allergic asthma compared to that in normal controls $\left[(6.53 \pm 2.17) \times 10^{-3}\right.$ vs. $(3.53 \pm 1.41) \times 10^{-3}, \mathrm{P}<0.001$; and $(10.02 \pm 0.80) \times 10^{-3}$ vs. $(8.83 \pm 1.01) \times 10^{-3}, \mathrm{P}<0.001$, respectively] (Fig. 2). These results were in agreement with our previous study (16) and confirmed the veracity of the selected asthmatic patients.

The correlation between GATA3 mRNA and IL-4, ROR- $\gamma \mathrm{t}$ mRNA and IL-17A was then analyzed. We observed that GATA3 mRNA expression was positively correlated with serum IL-4 levels $(r=0.583, \mathrm{P}<0.01)$, whereas there was no obvious correlation between ROR- $\gamma \mathrm{t}$ mRNA and serum IL-17A levels $(r=0.197, \mathrm{P}=0.406)$.

We also analyzed the correlation of CD39 mRNA with GATA3 and ROR- $\gamma \mathrm{t}$ mRNA expression and observed that CD39 mRNA expression was negatively correlated with GATA3 mRNA $(r=-0.424, P<0.01)$ and exhibited no obvious correlation with ROR- $\gamma \mathrm{t}$ mRNA expression ( $\mathrm{r}=-0.259, \mathrm{P}=0.122)$.

Decreased FoxP3 and TGF- $\beta$ levels are associated with of CD39 mRNA deficiency. In our study, we also investigated the

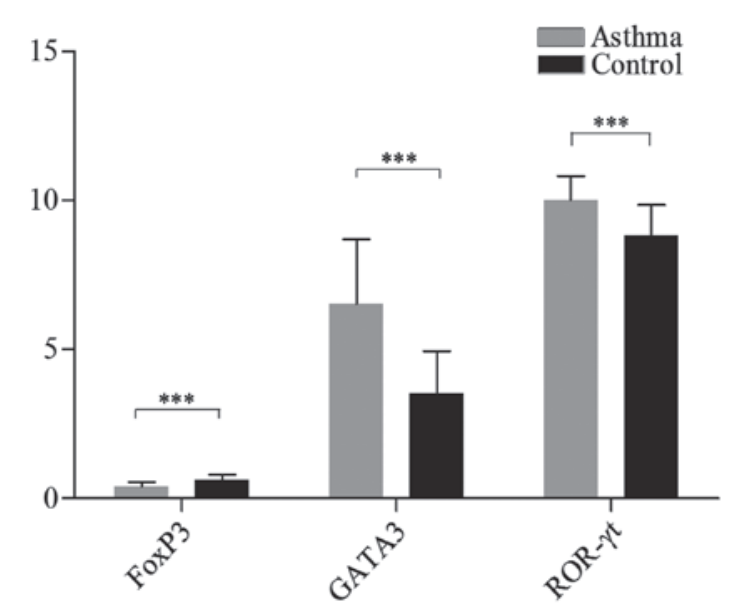

Figure 2. Comparison of Foxp3, GATA3 and ROR- $\gamma \mathrm{t}$ mRNA in peripheral blood mononuclear cells between patients with allergic asthma and normal controls. ${ }^{* * *} \mathrm{P}<0.001$. FoxP3, forkhead box P3; ROR- $\gamma$ t, RAR-related orphan receptor $\gamma$.

level of serum TGF- $\beta$ and FoxP3 mRNA expression in PBMCs and observed that serum TGF- $\beta$ and FoxP3 mRNA levels were markedly lower in patients with allergic asthma compared to those in normal controls $[66.15 \pm 33.30$ vs. $164.44 \pm 42.61$, $\mathrm{P}<0.01$; and $(0.40 \pm 0.15) \times 10^{-3}$ vs. $(0.64 \pm 0.16) \times 10^{-3}, \mathrm{P}<0.001$, respectively] (Table III and Fig. 2). Moreover, CD39 mRNA expression was positively correlated with serum TGF- $\beta$ and FoxP3 mRNA expression $(r=0.425, \mathrm{P}<0.05 ; \mathrm{r}=0.373, \mathrm{P}<0.05)$.

\section{Discussion}

In our study, we investigated the expression of CD39 mRNA in PBMCs. Our data indicated that CD39 mRNA expression was downregulated in allergic asthma. We hypothesized that the deficiency of CD39 mRNA in asthma, which leads to the absence of the anti-inflammatory effects of CD39, may promote the occurrence of asthma.

Imbalances in $\mathrm{T}$ helper (Th)1/Th2 and Th17/regulatory $\mathrm{T}$ cells (Treg cells) were also detected in patients with allergic asthma (15). Th2, Th17 and Treg cells exhibit unique cytokine and specific transcription factor profiles that instruct a specific differentiation program $(13,14,17)$. It is currently recognized that Th2-cell differentiation and IL-4 secretion is dependent on GATA3 (18). The differentiation and development of Th17 cells, which mainly secrete IL-17A, require ROR- $\gamma \mathrm{t}$ (19-21), whereas Treg cells require FoxP3 and mainly secrete TGF- $\beta$ (22). It is widely accepted that Th2 and Th17 cells are important contributors to inflammatory responses and airway remodeling $(18,23)$ and Treg cells play a central role in regulating the self-tolerance and homeostasis of the immune system (24). In our study, we observed that the deficiency of CD39 mRNA in PBMCs was negatively correlated with increased serum IL-4 and IL-17A levels and positively correlated with decreased serum TGF- $\beta$ levels. We hypothesized that the decreased CD39 may result in inflammatory damages in asthma by upregulating serum IL-4 and IL-17A, which mediate airway inflammation in asthma, and downregulating serum TGF- $\beta$, which is a soluble anti-inflammatory cytokine $(21,24)$. Previous studies demonstrated that 
increased GATA3 and ROR- $\gamma$ t and decreased FoxP3 expression mediate the inflammatory responses in asthma $(20,25,26)$. Moreover, CD73, another ectoenzyme, may act synergistically with CD39 to catalyze the conversion of extracellular ATP into immune suppressor adenosine. Subsequently, adenosine combines to the adenosine receptor $\mathrm{A} 2 \mathrm{~A}$, which is expressed on effector T (Teff) cells and Treg cells, inhibiting the activation and functions of Teff cells, such as inhibition of Th2 cell development and Th17 cell generation $(27,28)$ and promoting the expression of FoxP3 by Treg cells (29). Accordingly, we hypothesized that CD39 may regulate the levels of serum IL-4, IL-17A and TGF- $\beta$ by regulating GATA3, ROR- $\gamma$ t and FoxP3 expression. However, we observed that CD39 was negatively correlated with GATA3 and positively correlated with FoxP3, whereas there was no obvious correlation of CD39 with ROR- $\gamma \mathrm{t}$. The role of the signaling pathway of CD39, CD73 and A2AR in asthma may differ from that in multiple sclerosis and renal ischemia-reperfusion injury. Moreover, other immune cells also express IL-17A in addition to the Th17 cells (30). Thus we hypothesized that CD39 may control IL-17A levels by regulating other IL-17A-producing cells.

In conclusion, we demonstrated that CD39 mRNA expression was downregulated in the peripheral blood of patients with asthma, which was associated with serum IL-4 and IL-17A levels and the expression of GATA3 and FoxP3 mRNA, whereas it was not associated with ROR- $\gamma \mathrm{t}$ mRNA expression. Therefore, the deficiency of C0D39 mRNA may be involved in the occurrence and progression of allergic asthma.

\section{References}

1. Maliszewski CR, Delespesse GJ, Schoenborn MA, et al: The CD39 lymphoid cell activation antigen. Molecular cloning and structural characterization. J Immunol 153: 3574-3583, 1994.

2. Koziak E, Sevigny J, Robson SC, Siegel JB and Kaczmarek K: Analysis of CD39/ATP diphosphohydrolase (ATPDase) expression in endothelial cells, platelets and leukocytes. Thromb Haemost 82: 1538-1544, 1999.

3. Day YJ, Huang L, Ye H, Li L, Linden J and Okusa MD: Renal ischemia-reperfusion injury and adenosine $2 \mathrm{~A}$ receptor-mediated tissue protection: the role of $\mathrm{CD}^{+} \mathrm{T}$ cells and IFN-gamma. J Immunol 176: 3108-3114, 2006.

4. Ohta A and Sitkovsky M: Role of G-protein-coupled adenosine receptors in downregulation of inflammation and protection from tissue damage. Nature 414: 916-920, 2001.

5. Erdmann AA, Gao ZG, Jung U, Foley J, Borenstein T, Jacobson KA and Fowler DH: Activation of Th1 and Tc1 cell adenosine A2A receptors directly inhibits IL-2 secretion in vitro and IL-2-driven expansion in vivo. Blood 105: 4707-4714, 2005.

6. Sipka S, Kovacs I, Szanto S, Szegedi G, Brugos L, Bruckner G and Jozsef Szentmiklosi A: Adenosine inhibits the release of interleukin-1beta in activated human peripheral mononuclear cells. Cytokine 31: 258-263, 2005.

7. Lappas CM, Rieger JM and Linden J: A2A adenosine receptor induction inhibits IFN-gamma production in murine $\mathrm{CD}^{+}$ T cells. J Immunol 174: 1073-1080, 2005.

8. Imai M, Goepfert C, Kaczmarek E and Robson SC: CD39 modulates IL-1 release from activated endothelial cells. Biochem Biophys Res Commun 270: 272-278, 2000.

9. Warny M, Aboudola S, Robson SC, Sevigny J, Communi D, Soltoff SP and Kelly CP: P2Y 6 nucleotide receptor mediates monocyte interleukin-8 production in response to UDP or lipopolysaccharide. J Biol Chem 276: 26051-26056, 2001.
10. la Sala A, Ferrari D, Corinti S, Cavani A, Di Virgilio F and Girolomoni G: Extracellular ATP induces a distorted maturation of dendritic cells and inhibits their capacity to initiate Th1 responses. J Immunol 166: 1611-1617, 2001.

11. Deaglio S, Dwyer KM, Gao W, et al: Adenosine generation catalyzed by CD39 and CD73 expressed on regulatory T cells mediates immune suppression. J Exp Med 204: 1257-1265, 2007.

12. Huang S, Apasov S, Koshiba M and Sitkovsky M: Role of A2a extracellular adenosine receptor-mediated signaling in adenosine-mediated inhibition of T-cell activation and expansion. Blood 90: 1600-1610, 1997.

13. Zhou L, Chong MM and Littman DR: Plasticity of $\mathrm{CD}^{+}{ }^{+} \mathrm{T}$ cell lineage differentiation. Immunity 30: 646-655, 2009.

14. Dong C: TH17 cells in development: an updated view of their molecular identity and genetic programming. Nat Rev Immunol 8: 337-348, 2008.

15. Shi YH, Shi GC, Wan HY, et al: Coexistence of Th1/Th2 and Th17/Treg imbalances in patients with allergic asthma. Chin Med J (Engl) 124: 1951-1956, 2011.

16. Shi YH, Shi GC, Ma JY, AI XY, Zhu HX, Wan HY: Expression of T-bet, GATA-3, ROR $\gamma$ t and Foxp3 mRNA in the peripheral blood of allergic asthma. Journal of Internal Medicine Concepts and Practice 6: 113-116, 2011 (In Chinese).

17. Weaver CT, Harrington LE, Mangan PR, Gavrieli M and Murphy KM: Th17: an effector CD4 T cell lineage with regulatory T cell ties. Immunity 24: 677-688, 2006.

18. Zhu J, Yamane H, Cote-Sierra J, Guo L and Paul WE: GATA-3 promotes $\mathrm{Th} 2$ responses through three different mechanisms: induction of Th2 cytokine production, selective growth of Th2 cells and inhibition of Th1 cell-specific factors. Cell Res 16: 3-10, 2006.

19. Chen Q, Yang W, Gupta S, et al: IRF-4-binding protein inhibits interleukin-17 and interleukin-21 production by controlling the activity of IRF-4 transcription factor. Immunity 29: 899-911, 2008.

20. Ivanov II, McKenzie BS, Zhou L, et al: The orphan nuclear receptor RORgammat directs the differentiation program of proinflammatory IL-17+ $\mathrm{T}$ helper cells. Cell 126: 1121-1133, 2006.

21. Tesmer LA, Lundy SK, Sarkar S and Fox DA: Th17 cells in human disease. Immunol Rev 223: 87-113, 2008.

22. Josefowicz SZ and Rudensky A: Control of regulatory $\mathrm{T}$ cell lineage commitment and maintenance. Immunity 30: 616-625, 2009.

23. Zhao J, Lloyd CM and Noble A: Th17 responses in chronic allergic airway inflammation abrogate regulatory T-cell-mediated tolerance and contribute to airway remodeling. Mucosal Immunol 6: 335-346, 2013.

24. Shevach EM: $\mathrm{CD}^{+} \mathrm{CD} 25^{+}$suppressor T cells: more questions than answers. Nat Rev Immunol 2: 389-400, 2002.

25. Erpenbeck VJ, Hagenberg A, Krentel H, et al: Regulation of GATA3, c-maf and T-bet mRNA expression in bronchoalveolar lavage cells and bronchial biopsies after segmental allergen challenge. Int Arch Allergy Immunol 139: 306-316, 2006.

26. Curotto de Lafaille MA, Kutchukhidze N, Shen S, et al: Adaptive Foxp $3^{+}$regulatory T cell-dependent and -independent control of allergic inflammation. Immunity 29: 114-126, 2008.

27. Borsellino G, Kleinewietfeld M, Di Mitri D, et al: Expression of ectonucleotidase CD39 by Foxp3 ${ }^{+}$Treg cells: hydrolysis of extracellular ATP and immune suppression. Blood 110: 1225-1232, 2007.

28. Fletcher JM, Lonergan $\mathrm{R}$, Costelloe L, et al: $\mathrm{CD} 39^{+} \mathrm{Foxp} 3^{+}$regulatory T cells suppress pathogenic Th17 cells and are impaired in multiple sclerosis. J Immunol 183: 7602-7610, 2009.

29. Ohta A, Kini R, Ohta A, Subramanian M, Madasu M and Sitkovsky M: The development and immunosuppressive functions of $\mathrm{CD}^{+} \mathrm{CD} 25^{+} \mathrm{FoxP}^{+}$regulatory $\mathrm{T}$ cells are under influence of the adenosine-A2A adenosine receptor pathway. Front Immunol 3: 190, 2012.

30. Michel ML, Pang DJ, Haque SF, Potocnik AJ, Pennington DJ and Hayday AC: Interleukin 7 (IL-7) selectively promotes mouse and human IL-17-producing $\gamma \delta$ cells. Proc Natl Acad Sci USA 109: 17549-17554, 2012. 